Section Editor Mitchell S.V. Elkind, MD, MS

Julia B. Whitlock, MD

Glen T. Robinson, MD

Joseph P. Whitlock, MD

Brynn K. Dredla, MD

Kevin M. Barrett, MD

Correspondence to

Dr. Barrett:

barrett.kevin@mayo.edu

Mystery Case:

\title{
A 21-year-old man with visual loss following marijuana use
}

\section{SECTION 1}

A 21-year-old man with no reported medical history presented to the emergency department complaining of bilateral blurry vision. His symptoms began abruptly 2 days prior to presentation, preceded by a thunderclap headache the week prior. Initial evaluation at an outside emergency department found a urine drug screen positive for cannabis, and his symptoms were misattributed to marijuana intoxication. The patient was a chronic, daily marijuana user. There was no family history of migraine, early-onset cerebrovascular or cardiovascular disease, or hypercoagulable state.

The neurologic examination was notable for uncorrected near visual acuity of 20/30 bilaterally. A right homonymous hemianopia was found on confrontational visual field testing. Pupillary reactivity and ocular motility was normal. No papilledema was evident. Facial and palatoglossal movements were normal. The patient was unable to read simple or complex sentences. Writing, fluency, repetition, comprehension, and object naming were intact. The remainder of the neurologic examination had normal results. There were no dermatologic or ocular abnormalities.

\section{Questions for consideration:}

1. What is the most likely neuroanatomic localization based on the examination findings?

2. What differential diagnoses should be considered at this point? 


\section{SECTION 2}

Right homonymous hemianopia localizes to the retrochiasmal afferent visual pathway (optic tract, optic radiation, or primary visual cortex) in the left hemisphere. The inability to read with preserved writing is termed "alexia without agraphia," which is a disconnection syndrome caused by involvement of the splenium of the corpus callosum. A lesion involving the left occipital cortex and adjacent splenium functionally disconnects the intact right hemispheric visual cortex from the left hemispheric language areas necessary for reading; this deficit is seen in left posterior cerebral artery (PCA) distribution infarcts. Additional clinical findings associated with left PCA infarction include hemiachromatopsia (impaired color vision), palinopsia, micropsia, macropsia (visuopsychic phenomena characterized by persistent image in the blind hemifield, and appearance of objects smaller or larger than expected, respectively), visual agnosia, Gerstmann syndrome (acalculia, agraphia, finger agnosia and right-left confusion), and aphasia (anomic or transcortical sensory). ${ }^{1}$ Occasionally a single trunk off the PCA (artery of Percheron) supplies the bilateral thalamus and midbrain; in such cases, infarction is hallmarked by lethargy, memory disturbance, thalamic aphasia, sensorimotor impairment, and ophthalmoplegia.

Abrupt symptom onset should prompt consideration of a vascular etiology such as ischemic or hemorrhagic stroke. The heralding thunderclap headache raises the possibility of subarachnoid hemorrhage, cervicocephalic dissection, cerebral venous thrombosis, or reversible cerebral vasoconstrictive syndrome. Primary or secondary complications related to marijuana or other illicit substances are considerations. Infectious, neoplastic, and demyelinating processes warrant consideration but were believed to be less likely.

Brain MRI with and without contrast showed acute bihemispheric infarction in multiple arterial territories (figure). The left PCA distribution acute infarction involved the visual cortex and splenium of the corpus callosum resulting in the clinical syndrome of alexia without agraphia. Gradient-echo
Figure Axial diffusion-weighted imaging sequence obtained at the level of the thalami

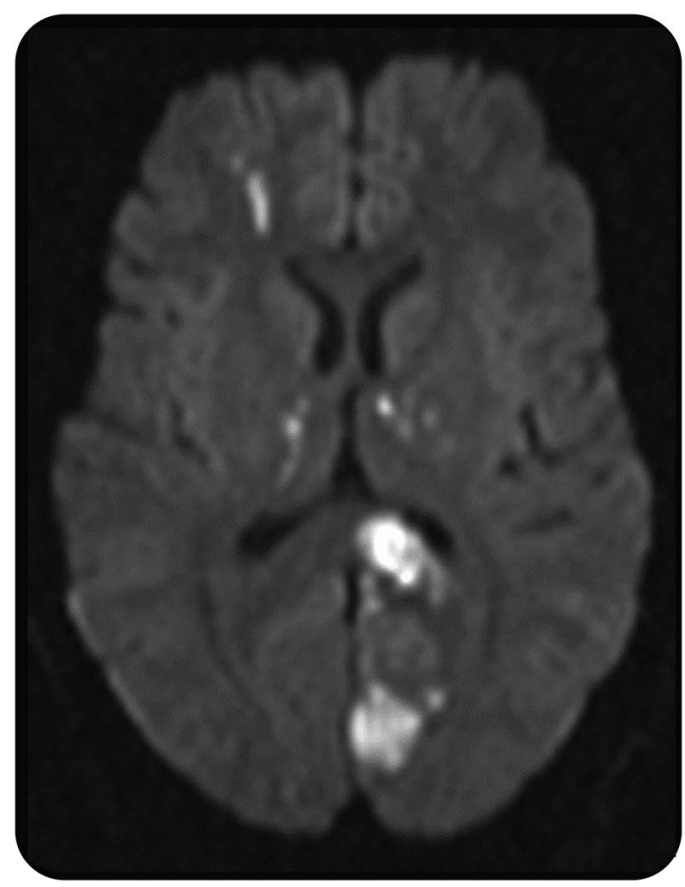

Multifocal, bihemispheric regions of restricted diffusion are seen with notable involvement of the calcarine and splenium of the corpus callosum.

sequences were unremarkable. Four-vessel cerebral angiogram was normal. Laboratory testing was remarkable for a serum creatinine of 1.2 and EKG demonstrated a right bundle branch block. Evaluation with transthoracic and transesophageal echocardiogram and cardiac MRI were normal. Investigation for inherited or acquired prothrombotic states revealed heterozygosity for MTHFR mutation; homocysteine level was normal.

\section{Questions for consideration:}

1. What are the most common causes of stroke in the young?

2. What is the relationship between marijuana use and stroke? 


\section{SECTION 3}

Approximately $5 \%$ of strokes occur in young adults age $15-45$ years. In young adults with arterial ischemic stroke (AIS), cardioembolism accounts for $20 \%-30 \%$, cervicocephalic dissection $10 \%-25 \%$, premature largeartery atherosclerosis $8 \%$, small vessel disease $14 \%$, vasculitis $7 \%$, reversible cerebral vasoconstriction syndrome $1 \%$, and Moyamoya $1 \%$. Prothrombotic states, inherited causes, substance abuse, transient cerebral arteriopathy, and postinfectious vasculopathy (varicella-zoster virus) are also important considerations. Cervicocephalic dissection may be associated with fibromuscular dysplasia, Ehlers-Danlos syndrome, Marfan syndrome, coarctation of the aorta, and Moyamoya. A bimodal age distribution is seen in Moyamoya with pediatric populations (first decade of life) and in adults age 30-40 years. The incidence of pediatric Moyamoya in the United States is 0.086 per 100,000, although the incidence increases in Asians and African Americans. This entity accounts for roughly $6 \%$ of childhood AIS in Western countries.

Genetic susceptibility should be considered in young patients with stroke; a family history of stroke should prompt consideration of monogenic disorders that include stroke as a phenotype. Sickle cell disease is a significant hematologic contributor to arterial stroke due to prothrombotic state and progressive vasculopathy. The frequency of factor $\mathrm{V}$ Leiden mutation and antiphospholipid syndrome is $8 \%$ and $6 \%$, respectively. Cerebral autosomal dominant arteriopathy with subcortical infarcts and leukoencephalopathy is seen in $1 \%$, similar to mitochondrial disorders (1\%). The incidence of Fabry disease
(FD) in young adults with unexplained stroke may be up to $1.2 \%$.

Active malignancy leading to prothrombotic state is thought to contribute $1 \%$ of stroke. Drug-induced AIS has a similar frequency of $1 \%$. Migraine is another risk factor, thought to be the cause in $1 \%-$ $5 \%$. Despite thorough testing, cryptogenic stroke accounts for approximately one-third of AIS in both young adults and children. ${ }^{2-4}$

The association between marijuana use and stroke is unclear; fewer than 60 cases have been reported citing a temporal relationship. A causal relationship has not been established, largely due to lack of extensive neurovascular imaging and confounding factors including lifestyle and genetic predisposition. Postulated downstream effects of cannabis include impaired cerebral autoregulation, labile blood pressure, cardiac arrhythmias, vasculopathy, vasospasm, reversible cerebral vasoconstriction syndrome, and multifocal intracranial stenosis. The latter 2 are strong considerations in the mechanical pathogenesis of stroke associated with marijuana use. ${ }^{5}$

Additional family history was elicited; the patient's sister developed progressive visual deterioration and painful acroparesthesias during adolescence. A maternal half-uncle developed early-onset renal failure requiring hemodialysis at age 32 years. The patient was able to recall a personal history of painful acroparesthesias beginning in adolescence.

\section{Question for consideration:}

1. What additional testing should be considered in light of the family history? 


\section{SECTION 4}

Serum $\alpha$-galactosidase A activity was found to be zero, strongly suggestive of FD. This patient had multisystem manifestations of FD, including abnormal cardiac conduction, arterial stroke, and early renal dysfunction. No angiokeratomas were present. Treatment with enzyme replacement was recommended prior to molecular testing results, given the absence of GLA enzyme activity and family history. In addition to genetic counseling, he was referred for hematologic, ophthalmologic, cardiology, nephrology, and dermatologic evaluations.

DISCUSSION FD is an X-liked genetic disorder associated with mutations of the GLA gene resulting in deficiency of $\alpha$-galactosidase A activity, a lysosomal enzyme involved in lipid metabolism. Inefficient breakdown of lipids causes endothelial accumulation of globotriaosylceramide (Gb-3) in the kidneys, eyes, nervous system, and cardiovascular system. The incidence of FD is estimated at $1: 40,000$ to $1: 117,000$ male births, likely an underestimation due to nonspecific presenting symptoms and variability of presentation leading to misdiagnosis. FD occurs in all ethnic and racial groups. ${ }^{6,7}$ Clinical manifestations include acroparesthesias (75\%, mean age at onset 10 years), angiokeratomas (greater than $70 \%$, mean age at onset 14 years), impaired arterial circulation, cardiomyopathy, and arrhythmia (69\% in males, 65\% in females), leading to increased risk of myocardial infarction; corneal dystrophy (62\% in males, 53\% in females); tinnitus and hearing loss (57\% in males, $47 \%$ in females); autonomic nervous system involvement including hypohydrosis, fever, and gastrointestinal discomfort (55\% in males, $50 \%$ in females); renal dysfunction $(50 \%$, mean age at onset $35-40$ years) and subsequent failure (17\% in males, $1 \%$ in females $)^{7}$; and stroke $(6.9 \%$ in males, $4.3 \%$ in females), predominantly in the posterior circulation due to basilar dolichoectasia. ${ }^{8}$ The mechanism of stroke is not clearly understood; however, hypotheses include vasculopathy from accumulation of Gb-3, abnormality in cerebral blood flow, and prothrombotic state. ${ }^{8}$ In our patient, chronic daily marijuana use may have conferred incremental risk to the development of arterial stroke given the underlying genetic predisposition from $\alpha$-galactosidase A deficiency. Stroke may be a harbinger of disease and occurs before a diagnosis of FD is made in roughly $50 \%$ of cases. ${ }^{8}$ Delays or diagnostic failure have negative implications on overall quality of life and survival time. The mean survival for men and women has been reported at $45.5 \pm 12.6$ years and $55.4 \pm 14.9$ years, respectively. Men frequently die of renal failure while cardiac disease is the most common cause of death in women. ${ }^{7}$
Enzyme replacement therapy (ERT) is costly but improves life expectancy to the fifth or sixth decade. ERT has yet to be proven to reduce future stroke risk. ${ }^{9}$ ERT should be considered for patients with FD in addition to antiplatelet therapy, blood pressure reduction, glycemic control, and lipid lowering for those with stroke. Clinical trials using pharmacologic chaperone therapy to facilitate proper tertiary structure of $\alpha$-galactosidase A show increased GLA activity and reduced Gb-3 accumulation in multiple organ systems. Chaperone therapy appears to be effective in mutations causing protein misfolding but is not effective for all mutations resulting in FD. ${ }^{6}$

Clinicians should retain a high index of suspicion for FD when evaluating stroke in the young, given the multisystem involvement and the need for comprehensive multispecialty care for the best prognosis.

\section{AUTHOR CONTRIBUTIONS}

J.B.W.: study concept and design, acquisition of data, analysis and interpretation, critical revision of the manuscript for important intellectual content. G.T.R.: acquisition of data, critical revision of the manuscript for important intellectual content. J.P.W.: acquisition of data, analysis and interpretation. B.K.D.: acquisition of data, analysis and interpretation. K.M.B.: analysis and interpretation, critical revision of the manuscript for important intellectual content, study supervision. All authors read and approved the final manuscript.

\section{STUDY FUNDING}

No targeted funding reported.

\section{DISCLOSURE}

J. Whitlock, G. Robinson, J. Whitlock, and B. Dredla report no disclosures relevant to the manuscript. K. Barrett receives support from the NINDS for his role in the Stroke Hyperglycemia Insulin Network Effort (SHINE) trial. Go to Neurology.org for full disclosures.

\section{REFERENCES}

1. Caplan LR. Posterior circulation cerebrovascular syndromes. In: UpToDate [online]. Available at: www. UpToDateInc.com. Accessed August 29, 2013.

2. Kittner SJ, Stern BJ, Wozniak M, et al. Cerebral infarction in young adults: the Baltimore Washington Cooperative Young Stroke Study. Neurology 1998;50:890-894.

3. Putaala J, Metso AJ, Metso TM, et al. Analysis of 1008 consecutive patients aged 15-49 with first-ever ischemic stroke: the Helsinki young stroke registry. Stroke 2009; 40:1195-1203.

4. Roach ES, Golomb MR, Adams R, et al. Management of stroke in infants and children. Stroke 2008;39:2644-2691.

5. Wolff V, Armspach JP, Lauer V, et al. Cannabis-related stroke: myth or reality? Stroke 2013;44:558-563.

6. Ishii S. Pharmacological chaperone therapy for Fabry disease. Proc Jpn Acad Ser B Phys Biol Sci 2012;88: 18-30.

7. Mehta A, Ricci R, Widmer U, et al. Fabry disease defined: baseline clinical manifestations of 366 patients in the Fabry Outcome Survey. Eur J Clin Invest 2004;34:236-242.

8. Sims K, Politei J, Banikazemi M, Lee P. Stroke in Fabry disease occurs before diagnosis and in the absence of other clinical events: natural history from the Fabry Registry. Stroke 2009;40:788-794. 
9. Cruse R. Neurologic manifestations of Fabry disease. In UpToDate [online]. Available at: www.UpToDateInc. com. Accessed April 2, 2013.

\section{MYSTERY CASE RESPONSES}

The Mystery Case series was initiated by the Neurology ${ }^{\circledR}$ Resident \& Fellow Section to develop the clinical reasoning skills of trainees. Residency programs, medical student preceptors, and individuals were invited to use this Mystery Case as an educational tool. Responses were solicited through a group e-mail sent to the American Academy of Neurology Consortium of Neurology Residents and Fellows and through social media.

All the respondents for this Mystery Case identified the patient's clinical syndrome as pure alexiaalso known as alexia without agraphia-and localized this syndrome to the dominant occipital lobe and splenium of the corpus callosum. A total of $75 \%$ of respondents recognized that the patient's clinical findings and family history are suggestive of FD; each of these respondents correctly identified $\alpha$-galactosidase activity as the appropriate diagnostic test for this disorder.

The most complete answer came from Jeremy Cutsforth-Gregory from Mayo Clinic, who noted that the diagnostic test of choice for female patients is molecular genetic testing of the GLA gene. In heterozygous females, $\alpha$-galactosidase activity is an unreliable indicator and may be within the normal range.

This case highlights a rare but treatable disorder with both neurologic and systemic manifestations, and underscores the importance of screening for systemic involvement to reach an accurate diagnosis.

Andrew Schepmyer, MD

University of British Columbia 


\section{Neurology}

\section{Mystery Case: A 21-year-old man with visual loss following marijuana use}

Julia B. Whitlock, Glen T. Robinson, Joseph P. Whitlock, et al.

Neurology 2015;84; $165-\mathrm{e} 169$

DOI 10.1212/WNL.0000000000001627

\section{This information is current as of May 25, 2015}

\section{Updated Information \& Services}

References

Subspecialty Collections

Permissions \& Licensing

Reprints including high resolution figures, can be found at: http://n.neurology.org/content/84/21/e165.full

This article cites 7 articles, 5 of which you can access for free at: http://n.neurology.org/content/84/21/e165.full\#ref-list-1

This article, along with others on similar topics, appears in the following collection(s):

All Cerebrovascular disease/Stroke

http://n.neurology.org/cgi/collection/all_cerebrovascular_disease_strok e

Infarction

http://n.neurology.org/cgi/collection/infarction

Metabolic disease (inherited)

http://n.neurology.org/cgi/collection/metabolic_disease_inherited Stroke in young adults

http://n.neurology.org/cgi/collection/stroke_in_young_adults

Visual fields

http://n.neurology.org/cgi/collection/visual_fields

Information about reproducing this article in parts (figures,tables) or in its entirety can be found online at:

http://www.neurology.org/about/about_the_journal\#permissions

Information about ordering reprints can be found online:

http://n.neurology.org/subscribers/advertise

Neurology ${ }^{\circledR}$ is the official journal of the American Academy of Neurology. Published continuously since 1951 , it is now a weekly with 48 issues per year. Copyright @ 2015 American Academy of Neurology. All rights reserved. Print ISSN: 0028-3878. Online ISSN: 1526-632X.

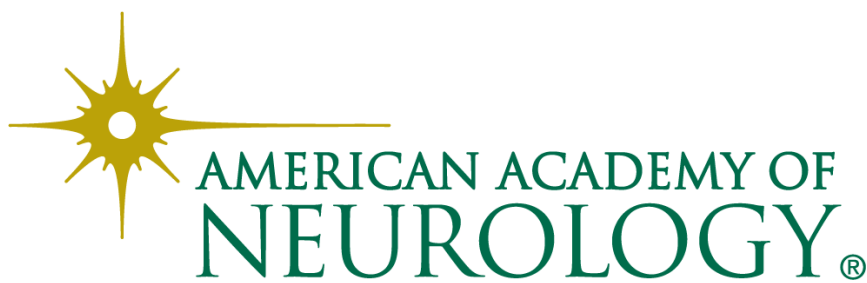

